\title{
WILDERNESS IMAGE
}

\section{Fatal Avalanche on Mount Everest}

\author{
Dale R. Wagner, PhD, FACSM
}

Kinesiology \& Health Science Department, Utah State University, Logan, UT

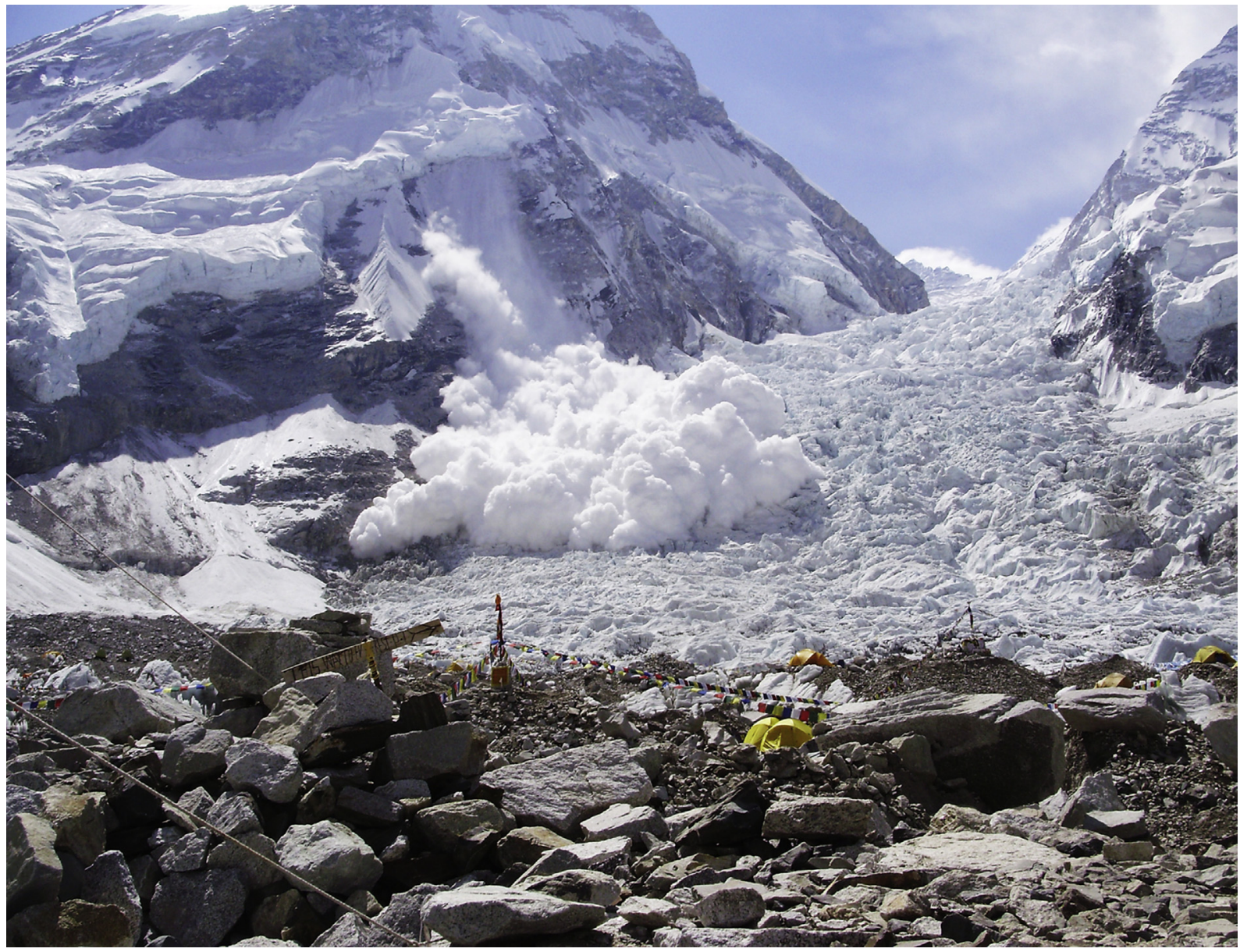

On the morning of May 7, 2009, a section of the hanging glacier on the west shoulder of Mount Everest broke free, creating this avalanche that spread across the Khumbu icefall. Avalanches are common in this area. Climbers in Everest Base Camp become accustomed to hearing distant avalanches and somewhat desensitized to it, in the same way that a solder in combat might become accustomed to nonthreatening distant mortar explosions. However, the sound and proximity of this avalanche caused everyone to take notice immediately. Unfortunately, Lhakpa Nuru Sherpa, age $33 \mathrm{y}$, perished in this avalanche.

Photo taken from Base Camp (GPS: 2800'15.60” N and $86^{\circ} 51^{\prime} 20.39^{\prime \prime} \mathrm{E}$ ). 